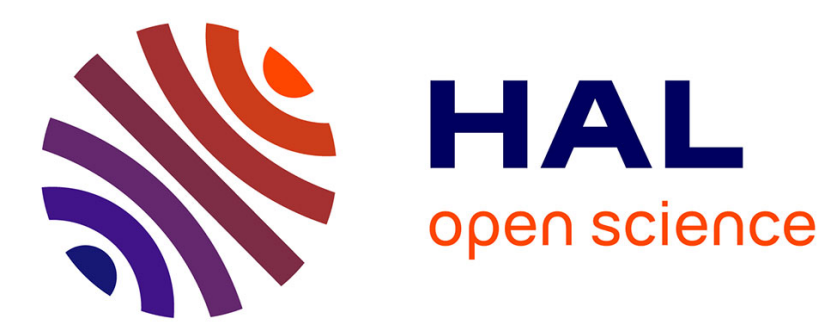

\title{
Multitemporal observations of sugarcane by TerraSAR-X sensor
}

\author{
N. Baghdadi, P. Todoroff, Mehrez Zribi
}

\section{To cite this version:}

N. Baghdadi, P. Todoroff, Mehrez Zribi. Multitemporal observations of sugarcane by TerraSAR-X sensor. IGARSS 2011, Jul 2011, Vancouver, Canada. p. 1401 - p. 1404. hal-00617520

\section{HAL Id: hal-00617520 \\ https://hal.science/hal-00617520}

Submitted on 29 Aug 2011

HAL is a multi-disciplinary open access archive for the deposit and dissemination of scientific research documents, whether they are published or not. The documents may come from teaching and research institutions in France or abroad, or from public or private research centers.
L'archive ouverte pluridisciplinaire HAL, est destinée au dépôt et à la diffusion de documents scientifiques de niveau recherche, publiés ou non, émanant des établissements d'enseignement et de recherche français ou étrangers, des laboratoires publics ou privés. 


\title{
Multitemporal observations of sugarcane by TerraSAR-X sensor
}

\author{
Nicolas Baghdadi ${ }^{1}$, Pierre Todoroff ${ }^{2}$, Mehrez Zribi ${ }^{3}$ \\ ${ }^{1}$ CEMAGREF, UMR TETIS, 500 rue François Breton \\ 34093 Montpellier cedex 5, France - baghdadi@teledetection.fr \\ ${ }^{2}$ CIRAD- Reunion, Ligne Paradis, 97410 Saint-Pierre, France \\ ${ }^{3}$ CESBIO, 18 av. Edouard Belin, bpi 2801, 31401 Toulouse cedex 9, France
}

\begin{abstract}
The potential of TerraSAR-X (X-band) in monitoring sugarcane growth was investigated on Reunion Island. Multitemporal TerraSAR data acquired at various incidence angles $\left(17^{\circ}\right.$, $31^{\circ}, 37^{\circ}, 47^{\circ}, 58^{\circ}$ ) and polarizations ( $\left.\mathrm{HH}, \mathrm{HV}, \mathrm{VV}\right)$ were analyzed in order to study the behaviour of SAR (synthetic aperture radar) signal as a function of sugarcane height. The potential of TerraSAR for mapping the sugarcane harvest was also studied. Radar signal increased quickly with crop height until a threshold height, which depended on polarization and incidence angle. Beyond this threshold, the signal increased only slightly, remained constant, or even decreased. TerraSAR data showed that after strong rains the soil contribution for the backscattering of sugarcane fields can be consequent for canes with heights of terminal visible dewlap (htvd) less than $50 \mathrm{~cm}$ (total cane heights around $155 \mathrm{~cm}$ ). Finally, TerraSAR data at high spatial resolution were shown to be useful for monitoring sugarcane harvest when the fields are of small size or when the cut is spread out in time. The radar incidence of $37^{\circ}$ is more suitable to monitor the sugarcane harvest.
\end{abstract}

Keywords - Sugarcane crop, TerraSAR-X, Reunion Island

\section{INTRODUCTION}

Sugarcane is one of the most important crops in the tropics, with a global production estimated at 1,250 million tons a year and a cropped area of about 20 millions hectares. One of the main needs expressed by sugarcane industries is to have information on the harvest progress throughout the harvest season. The dynamic mapping of sugarcane harvest on a large spatial scale allows optimized cutter deployment, transport operations, efficiency of factories, and finally permits a better estimation of the effective yield.

The use of optical images is sometimes limited because of atmospheric conditions and cloud cover. Indeed, the interval between two cloud-free images is sometimes too long (more than 2 months); this makes difficult the discrimination between a standing crop and the regrowth in a field harvested at the beginning of the harvest campaign. On the contrary, Synthetic Aperture Radar (SAR) provides measurements day and night, regardless of meteorological conditions. With their frequent revisits, SAR sensors are very useful remote sensing data sources for agriculture monitoring in tropical regions. The new generation SAR sensors, such as TerraSAR-X, allow the acquisition of images at very high spatial resolution $(\sim 1 \mathrm{~m})$.
Moreover, its short revisit interval makes it possible to monitor the harvest with high temporal frequency (daily to weekly).

The SAR sensors currently operational are TerraSAR-X (X-band), COSMO-SkyMed (X-band), PALSAR/ALOS (Lband), ASAR/ENVISAT (C-band), RADARSAT-1/2 (Cband), and ERS-2 (C-band). New generation SAR sensors (TerraSAR-X, PALSAR/ALOS, RADARSAT-2, COSMOSkyMed) should considerably increase the current capacities for monitoring continental surfaces by providing data more frequently than before and at high spatial resolution (metric for TerraSAR-X). The increasing number of SAR satellites and the high revisit interval of new sensors (TerraSAR-X and COSMO-SkyMed) makes it possible to follow the harvest season with high temporal frequency (daily to weekly).

This study examined the relationship between TerraSAR signal and sugarcane height as a function of instrumental parameters (polarization and incidence), and precipitation. In addition, the potential of TerraSAR-X for mapping harvested sugarcane crop was studied.

\section{STUDY AREA AND DAT SET}

The study site covers a sugarcane farm located at the south of Reunion Island, close the town of Saint Pierre (latitude: $21^{\circ} 19^{\prime} \mathrm{S}$ - longitude: $55^{\circ} 31^{\prime} \mathrm{E}$; Figure 1). The study site is composed mainly of agricultural fields intended for growing sugarcane. Fifteen sugarcane fields of an average size of 9 ha were studied: $\{2,3,4,5,6.1,6.2,12.1,12.2,123,15,16,18$, $191,192,20\}$. These training fields extend on $4.5 \mathrm{~km}$ length approximately, between $100 \mathrm{~m}$ to $500 \mathrm{~m}$ altitude. TerraSAR-X images were acquired over our study site. The images belong to the KALIDEOS database set up by the CNES (French space Agency) [1].

64 TerraSAR-X images (X-band $\sim 9.65 \mathrm{GHz}$ ) were acquired between $14^{\text {th }}$ of December 2008 and $20^{\text {th }}$ of January 2010 with a great range of incidence angle $\left(17^{\circ}, 31^{\circ}, 37^{\circ}, 47^{\circ}\right.$ and $59^{\circ}$ ), and in mono- and dual-polarization modes ( $\mathrm{HH}, \mathrm{VV}$, $\mathrm{HH} / \mathrm{VV}, \mathrm{HH} / \mathrm{HV}, \mathrm{VH} / \mathrm{VV})$. The imaging modes used were Spotlight and Stripmap. The pixel spacing of TerraSAR images was between 1 and $3 \mathrm{~m}$.

Radiometric calibration using MGD (Multi Look Ground Range Detected) TerraSAR images was carried out in using the following equation [2]: 


$$
\sigma_{i}^{\circ}(d B)=10 \log _{10}\left(K s D N_{i}^{2}-N E B N\right)+10 \log _{10}\left(\sin \theta_{i}\right)
$$

This equation transforms the amplitude of backscattered signal for each pixel $\left(D N_{i}\right)$ into a backscattering coefficient $\left(\sigma^{\circ}{ }_{i}\right)$ in decibels. The calibration coefficient Ks (scaling gain value) varies within the range of $7.710^{-6}$ to $1.210^{-5}$, depending on radar incidence angle $\left(\theta_{i}\right)$ and polarization (low values for cross-polarizations or high incidences). NEBN is the Noise Equivalent Beta Naught $\left(K s D N_{i}^{2}\right)$. It represents the influence of different noise contributions to the SAR signal. The NEBN is described using a polynomial scaled with Ks. The polynomial coefficients are derived from the TerraSAR product file. All TerraSAR images were then georeferenced using GPS points.

The strong values of NEBN found for images acquired in Stripmap mode did not allow a calibration of many pixels because the term Ks.DN² was lower than the noise NEBN. This problem is very frequent for pixels corresponding to smooth areas (specular reflexion), such as harvested fields. Moreover, the results show that the influence of the noise is stronger for cross-polarizations than for co-polarizations because even if the NEBN is of the same order of magnitude for cross- and copolarizations, the term Ks. $\mathrm{DN}^{2}$ is weaker for crosspolarizations. Many pixels impossible to calibrate was also observed at high incidences. These aberrant pixels $\left(\mathrm{Ks}_{\mathrm{D}} \mathrm{DN}^{2}<\right.$ NEBN) were not used in the calculation of the statistics (for certain images, nearly $30 \%$ of aberrant pixels were found what represents a strong loss of information).

In practice, the mean backscattering coefficients were calculated from calibrated SAR images by averaging the linear $\sigma^{\circ}$ values of all pixels within reference fields or (sub-fields in the case where only a part of field is harvested).

Ground truth measurements of sugarcane height were performed on several reference fields from November 07, 2008 to June 06, 2009. On each reference field, two experimental areas of $1.5 \mathrm{~m} \mathrm{x} 1.5 \mathrm{~m}$ were used to collect the sugarcane height, number of stems and leaves. Ground measurements showed that the sugarcane in our study site grows about $25 \mathrm{~cm}$ per month during the five first months, $40 \mathrm{~cm}$ between the $6^{\text {th }}$ and $9^{\text {th }}$ month, and then of about $10-20 \mathrm{~cm}$ per month until reaching the mature height of the cane. The ground measurements of the sugarcane height correspond to the height of terminal visible dewlap (htvd). They exclude the leafy tops which have heights of the order of $55 \mathrm{~cm}$ for sugarcane with htvd of $20 \mathrm{~cm}, 105 \mathrm{~cm}$ for htvd of $50 \mathrm{~cm}$, and of $125 \mathrm{~cm}$ for htvd between 100 and $180 \mathrm{~cm}$. Beyond htvd of $180 \mathrm{~cm}$, the leafy top height is about $135 \mathrm{~cm}$. For our reference fields, the mean number of stems and leaves was about 17 and 77 per $\mathrm{m}^{2}$, respectively (with a standard deviation of about 7 and 30, respectively).

In addition, the farmer of our reference fields also provided the harvesting dates of each reference field. Daily precipitation data recorded at four meteorological stations located on the farm were also used: Bérive-2, Isautier-Bérive, Isautier-Foyer, and Isautier-Ringuin. The effect of soil moisture content was taken into account in this study using precipitation data. Indeed, soil moisture measurements were difficult to carry out because the terrain is inaccessible in rainy weather and the soil is covered with mulch (dead leaves).

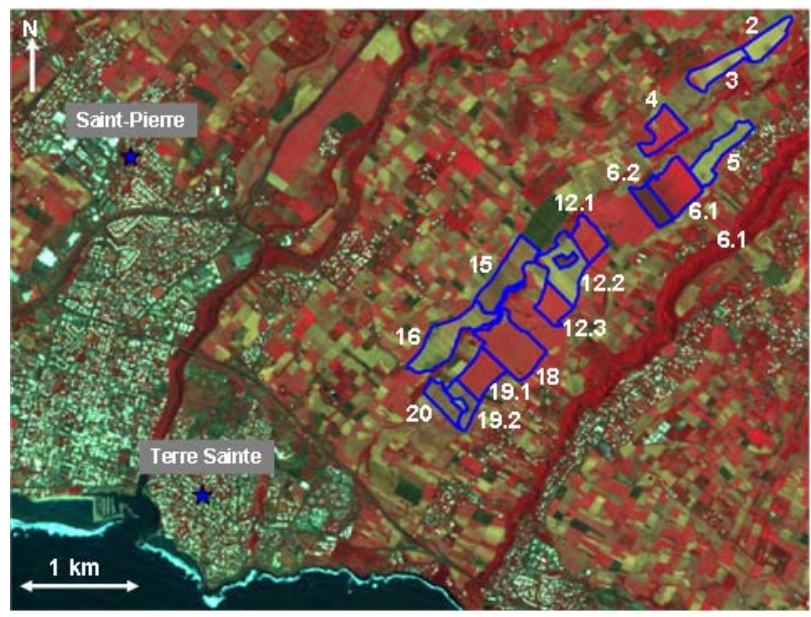

Figure 1. SPOT-5 image acquired over the study site in Reunion Island on October 21, 2008 (Red: band-3; Green: band-2; Blue: band1). Reference sugarcane fields are outlined in blue.

Table I

MAIN CHARACTERISTICS OF TERRASAR-X IMAGES.

\begin{tabular}{|c|c|c|c|}
\hline $\begin{array}{l}\text { Incidence } \\
\text { Angle }\left({ }^{\circ}\right)\end{array}$ & Polarization & $\begin{array}{c}\text { Imaging } \\
\text { mode }\end{array}$ & Date (dd/mm/yyyy) \\
\hline \multirow[b]{3}{*}{17} & $\mathrm{HH}$ & Spotlight & $16 / 03 / 2009 ; 07 / 04 / 2009 ; 29 / 04 / 2009 ; 10 / 05 / 2009$ \\
\hline & VV & Spotlight & $01 / 06 / 2009 ; 23 / 06 / 2009$ \\
\hline & $\mathrm{HH} / \mathrm{VV}$ & Spotlight & $\begin{array}{l}04 / 07 / 2009 ; 15 / 07 / 2009 ; 26 / 07 / 2009 ; 06 / 08 / 2009 ; \\
17 / 08 / 2009 ; 28 / 08 / 2009 ; 08 / 09 / 2009 ; 19 / 09 / 2009 \\
30 / 09 / 2009 ; 27 / 12 / 2009 ; 07 / 01 / 2010\end{array}$ \\
\hline \multirow{4}{*}{31} & $\mathrm{HH}$ & Spotlight & $18 / 03 / 2009 ; 01 / 05 / 2009 ; 23 / 05 / 2009$ \\
\hline & VV & Spotlight & $25 / 06 / 2009$ \\
\hline & $\mathrm{VH} / \mathrm{VV}$ & Stripmap & $\begin{array}{l}20 / 12 / 2008 ; 11 / 01 / 2009 ; 24 / 02 / 2009 ; 02 / 02 / 2009 ; \\
20 / 01 / 2010\end{array}$ \\
\hline & $\mathrm{HH} / \mathrm{HV}$ & Stripmap & $22 / 01 / 2009 ; 13 / 02 / 2009 ; 18 / 12 / 2009$ \\
\hline 37 & VV & Stripmap & $\begin{array}{l}01 / 08 / 2009 ; 03 / 09 / 2009 ; 06 / 10 / 2009 ; 17 / 10 / 2009 ; \\
28 / 10 / 2009 ; 08 / 11 / 2009 ; 11 / 12 / 2009 ; 13 / 01 / 2010\end{array}$ \\
\hline \multirow{4}{*}{47} & $\mathrm{HH}$ & Spotlight & $17 / 05 / 2009$ \\
\hline & VV & Spotlight & $08 / 06 / 2009 ; 30 / 06 / 2009$ \\
\hline & $\mathrm{VH} / \mathrm{VV}$ & Stripmap & $\begin{array}{l}14 / 12 / 2008 ; 25 / 12 / 2008 ; 27 / 01 / 2009 ; 18 / 02 / 2008 ; \\
14 / 01 / 2010\end{array}$ \\
\hline & $\mathrm{HH} / \mathrm{HV}$ & Stripmap & $16 / 01 / 2009 ; 07 / 02 / 2009 ; 14 / 01 / 2010$ \\
\hline \multirow{4}{*}{59} & $\mathrm{HH}$ & Spotlight & $17 / 03 / 2009 ; 08 / 04 / 2009 ; 30 / 04 / 2009 ; 11 / 05 / 2009$ \\
\hline & VV & Spotlight & $02 / 06 / 2009 ; 24 / 06 / 2009$ \\
\hline & $\mathrm{HH} / \mathrm{VV}$ & Spotlight & $\begin{array}{l}05 / 07 / 2009 ; 27 / 07 / 2009 ; 09 / 09 / 2009 ; 01 / 10 / 2009 ; \\
28 / 12 / 2009 ; 08 / 01 / 2010\end{array}$ \\
\hline & VH/VV & Spotlight & $16 / 07 / 2009 ; 07 / 08 / 2009 ; 29 / 08 / 2009 ; 20 / 09 / 2009$ \\
\hline
\end{tabular}

\section{RESULTS}

\section{Sensitivity of TerraSAR-X signal to sugarcane height}

The sensitivity of TerraSAR-X signals has been analyzed as a function of sugarcane height (htvd). Results show that the radar signal increases with the sugarcane height for the fields at the beginning of growth (htvd and total cane height respectively lower than $50 \mathrm{~cm}$ and $155 \mathrm{~cm}$, depending on incidence angle and polarization) (Figure 2) [3]. The growth of the sugarcane leads to increase of its height, number and size of leafs, and number and size of stems. This involves an increase of volume backscattering coefficient as well as attenuation of radar signal. However, the increase and decrease of backscatter caused by volume scattering and attenuation at the same time make radar signal reach saturation and then decrease when plant height is larger than $50 \mathrm{~cm} \mathrm{[3].}$ The dynamic of radar signal with the sugarcane height is slightly higher at $47^{\circ}$ than at $31^{\circ}$. A dynamic of $5 \mathrm{~dB}$ for $47^{\circ}$ 
and $2.5 \mathrm{~dB}$ for $31^{\circ}$ is observed for cane heights between 0 and approximately $50 \mathrm{~cm}$. Results show that $\sigma^{\circ}$ is strongly influenced by the soil moisture since a clear increase in the radar signal is observed after rainy episodes, in particular for young canes.
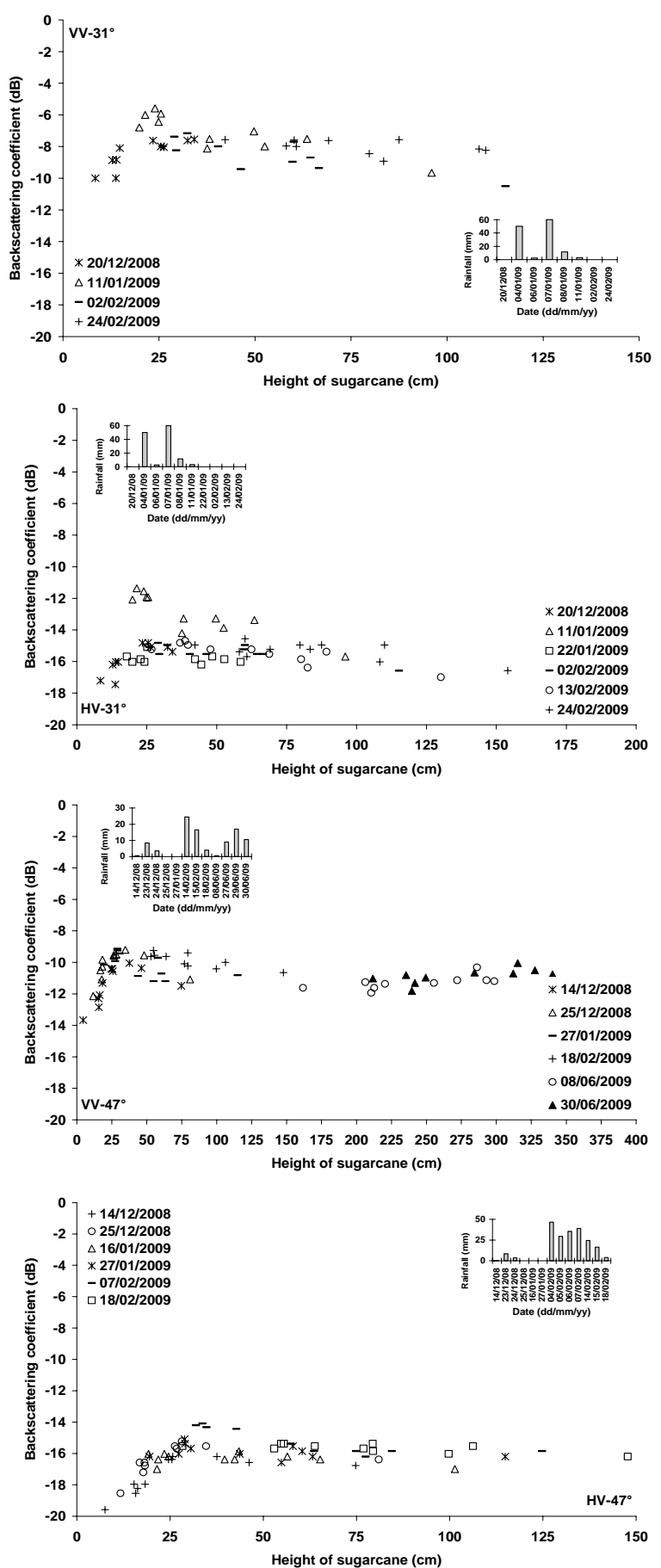

Figure 2. Radar backscattering coefficient as a function of plant height for VVand HV polarizations and incidence angle of $31^{\circ}$ and $47^{\circ}$. The sugarcane height corresponds to the height of terminal visible dewlap (htvd).
Results showed that the radar signal is very dependent on the precipitation particularly at low and medium incidence angles and for young canes. Indeed, at low and medium incidences, the soil contribution (influenced by soil moisture) to total backscattering could be important for cane heights lower than $95 \mathrm{~cm}$ (Figure 2). The soil effects are small for images acquired at high incidence angles and for sugarcanes with vegetation well developed. The decrease in radar signal for harvested fields could be reduced of 3-4 $\mathrm{dB}$ on images acquired after rainy period.

\section{Temporal backscatter and sugarcane harvest detection}

This study also examined the potential of different TerraSAR-X incidence angles and polarizations for mapping sugarcane harvests. Harvested fields are easily detected on SAR images if the image acquisition date is close to harvest date (ideally less than two months). Indeed, the harvest involves a decrease in the signal that can reach $7 \mathrm{~dB}\left(\mathrm{VV}-37^{\circ}\right)$ if the observation radar is relatively close to the harvesting date (few days). The incidences of $17^{\circ}$ and $58^{\circ}$ allow only partially the detection of the harvest because the decrease of radar signal after the cut is about $3 \mathrm{~dB}$ (Figure 3). Figure $3 \mathrm{~b}$ also shows that $\mathrm{HH}$ and $\mathrm{VV}$ polarizations are strongly correlated. The general trend is that the $\mathrm{HH}$ response is slightly higher than the VV (on the order of $1 \mathrm{~dB}$ ). This confirms the effect of higher attenuation at the $\mathrm{VV}$ polarization for sugarcanes with a vertical structure [4].
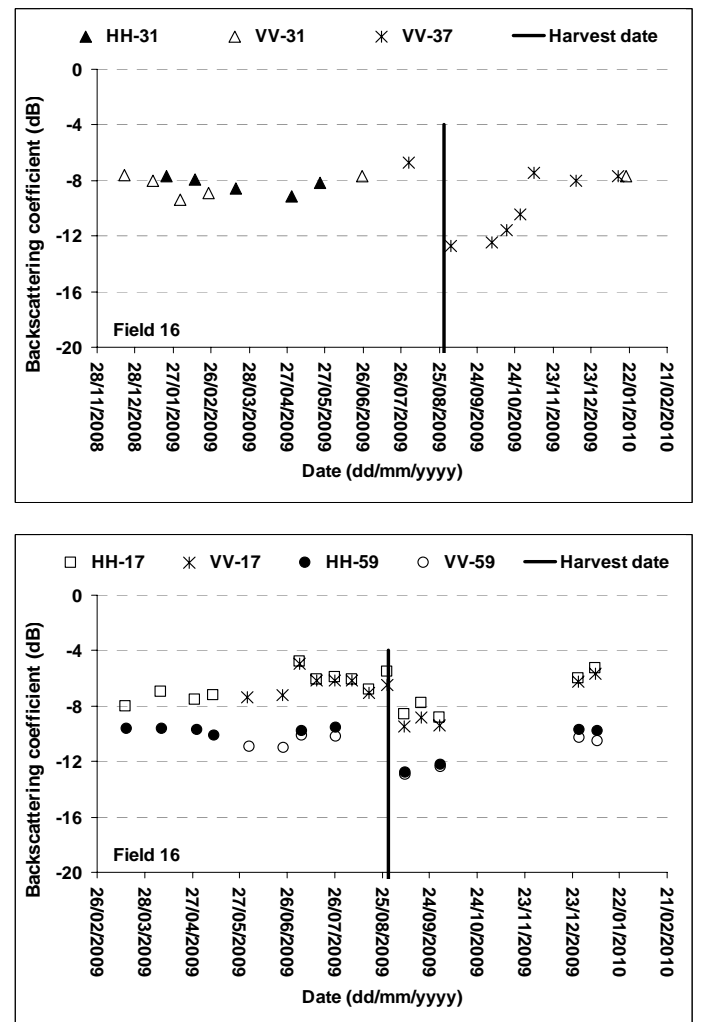

Figure 3. Temporal variation of TerraSAR signal for the reference sugarcane field 16 . (a) 31 and $37^{\circ}$, (b) $17^{\circ}$ and $59^{\circ}$.

Field 16 was harvested on August 29, 2009. 
Figure 4 shows segments of TerraSAR-X images acquired between August 01, 2009 and December 11, 2009 in VV polarization and with an incidence angle of $37^{\circ}$. The interpretation of TerraSAR images shows that the difference between the backscatter of mature cane and of harvested cane is well pronounced at medium incidence angles $\left(37^{\circ}\right)$. The images show high $\sigma^{\circ}$ for mature canes and low $\sigma^{\circ}$ for harvested fields. The discrimination between harvested fields or young canes (less than two months old) and canes of more than two months old is better with TerraSAR at $31^{\circ}-37^{\circ}$.

\section{CONCLUSIONS}

The objective of this study was to analyze the behaviour of TerraSAR signal as a function of sugarcane height. The radar backscattering coefficient of sampled fields was studied using ground truth measurements of sugarcane height, SPOT images, and harvest dates. The increasing trend of $\sigma^{\circ}$ as a function of sugarcane height is observed until a height htvd around $50 \mathrm{~cm}$, corresponding to total cane height around $155 \mathrm{~cm}$ (depends on incidence and polarization). The discrimination between young and mature canes is limited to fields harvested less than 2-3 months earlier (cane heights htvd between 0 and $50 \mathrm{~cm}$ ).

This study also examined the potential of different TerraSAR-X incidence angles and polarizations for mapping sugarcane harvest. Harvested fields are easily detected on SAR images if the image acquisition date is close to harvest date (ideally less than two months). Indeed, the harvest involves a decrease in the signal that can reach $7 \mathrm{~dB}\left(\mathrm{VV}-37^{\circ}\right)$ if the observation radar is relatively close to the harvesting date (few days). The incidences of $17^{\circ}$ and $58^{\circ}$ allow only partially the detection of the harvest because the decrease of radar signal after the cut is about $3 \mathrm{~dB}$.

Results showed that the radar signal could be very dependent on the soil moisture particularly at low and medium incidence angles and for young canes. Indeed, at low and medium incidences, the soil contribution (influenced by soil moisture) to total backscattering could be important for cane heights lower than $95 \mathrm{~cm}$. The soil effects are small for images acquired at high incidence angles and for sugarcanes with vegetation well developed. The decrease in radar signal for harvested fields could be reduced of $3-4 \mathrm{~dB}$ on images acquired after rainy period.

The very high spatial resolution (metric) of TerraSAR-X offers great potential for mapping harvested sugarcane crop. This SAR provides a diagnosis suited to agricultural areas where the parcels are of small size. The spatial resolution of TerraSAR images, between 1 and $3 \mathrm{~m}$ (for Spotlight and Stripmap modes) are well suited for sugarcane production areas dominated by small farmers as in Reunion Island with fields areas of about 1 ha on average. These results appear promising for the development of simplified algorithms for monitoring sugarcane harvest regardless of meteorological conditions, which are the main limitation with optical sensors.

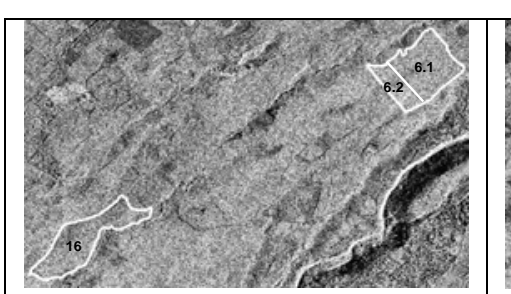

August 01, 2009

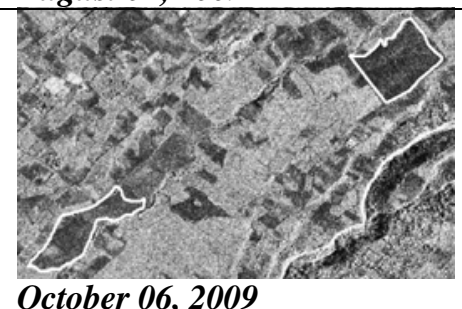

September, 03, 2009
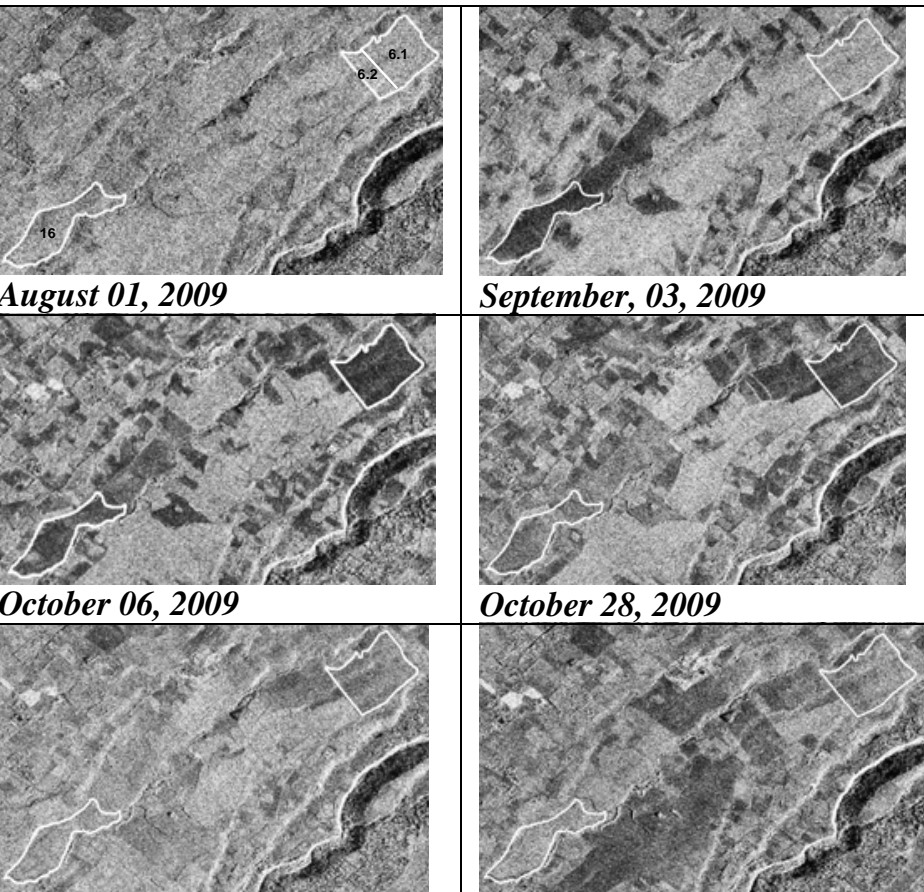

November 08, 2009
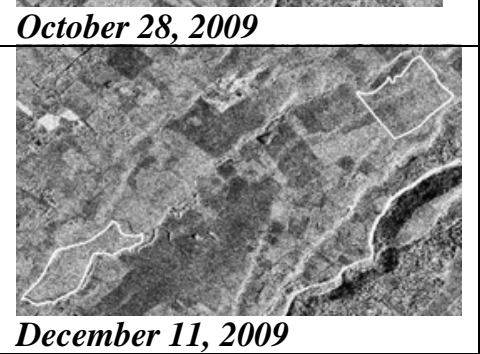

Figure 4. Comparison of several TerraSAR image segments for reference sugarcane fields $(6.1,6.2$, and 16). All images were acquired at incidence of $37^{\circ}$ and in VV polarization. Fields 6.1, 6.2, and 16 were harvested on September 10, October 03, and August 29, 2009, respectively.

\section{ACKNOWLEDGMENT}

The authors wish to thank CNES (French Space Agency) and DLR (German Space Agency) for kindly providing TerraSAR-X (proposal BOISSEZO_LAN0237). TerraSAR and SPOT images were obtained within the framework of Kalideos programme, set up by the CNES. Thanks are also due to Nathalie Boyer, Louis Paulin, and Raymond Nativel for their participation in the measurement surveys.

\section{REFERENCES}

[1] DeBoissezon, H., and Sand, A., 2006. Reference remote sensing data bases: Temporal series of calibrated and ortho-rectified satellite images for scientific use. Proceedings of recent advances in quantitative remote sensing, Valencia, Spain.

[2] Fritz, T., 2007. TerraSAR-X Ground Segment Level 1b Product Format Specification (10.12.2007), Doc.: TX-GS-DD-3307, Issue, 1.3, 257 pages, http://www.dlr.de/tsx/documentation/TX-GS-DD-3307_Level1b-Product-Format-Specification_1.3.pdf.

[3] Baghdadi, N., Cresson, R., Todoroff, P., and Soizic, M., 2010. Multitemporal observations of sugarcane by TerraSAR-X images. Sensors, 10(10), 8899-8919; doi:10.3390/s101008899

[4] Le Toan, T., Laur, H., Mougin, E., Lopes, A., 1989. Multitemporal and dual-polarization observations of agricultural vegetation covers by Xband SAR images. IEEE Transactions on Geoscience and Remote Sensing, 27 (6), 709-718. 